\title{
The Role of Social Networks on Socialization and Political Participation of Political science Students of Islamic Azad University, South Tehran Branch (2007- 2017)
}

Garineh Keshishyan Siraki*

Assistant professor, Islamic Azad University, South Tehran Branch, Tehran, Iran

\begin{abstract}
:
The present study was conducted with the aim of analyzing the impact of social networks on political socialization and political participation of political science students of the Islamic Azad University of Tehran, Tehran south branch during 2007-2017. This article is a descriptive-survey research based on the theory of planned behavior and has been done based on random sampling with a population of 280 samples. The findings indicate that $93 \%$ of students use social media and spend a significant part of their study hours on social networks, which mainly include Telegram, Instagram, Facebook, Twitter and WhatsApp. The variables related to social networks affect the socialization and political participation of students, and the extent of the impact of social networks on encouraging individuals to participate in the election as a component of political socialization is positive and significant. This finding and other findings are a positive and significant impact of social networks on the attitudes, values and norms, attitudes and behaviors of political science students as a sample population, and thus the hypothesis of this research has been confirmed.
\end{abstract}

Key Words: Political Socialization, Political Participation, Social Networking, Political Science Students, Islamic Azad University

*Corresponding Author's Email: g.keshishyan71@gmail.com 


\section{Problem statement:}

Nowadays, the spread of information and communication technologies has affected the various dimensions of political, social, cultural, security and economic life of human beings. With the dimming of the importance of time and space and the need for a common place to communicate, people can more easily communicate with one another in cyberspace. This new form of communication has changed the community, culture and identity of individuals. The features of cyber-communication provide different conditions for face-to-face relationships. The speed of action, anonymity, etc., provides the same space, regardless of the requirements of gender, class, ethnicity, race, and place, which creates different experiences for users. The interactions that take place in this space provide Internet users with a new mindset and tendency that can change their behavior and interactions in the real world, anyway, and, in fact, their socialization process, especially in the political arena will be affected. If political socialization is a continuous process of learning, whereby individuals, through acquisitions and experiences, acquire their duties, rights and roles, in particular their political duties in society, the development of cyberspace and expansion of Social networks are one of the new ways in which this process can be strengthened and even as a tool for changing or adjusting values, attitudes, institutions, customs and beliefs, including political issues in the process of transition from generation to the other generation works.

Social networks that are considered as an important part of interactive media and their content is fully provided by users with diverse tastes and different thoughts; and, of course, in such a space, there is the ability to generate content by any individual with any number of users, and even the administrators of these networks; hence, these networks, are in line with the circulation of their production, have a special place in the emergence of tastes, norms and values of the social community in a wide range of users, and are effective in changing the way people behave. The emergence of new habits, changing and creating the interaction of citizens and the formation of new cultures from the effects and consequences of the existence of these mass and social media were effective in the lives of peoples of the last decade.

The great interest and popularity of social networking users and their presence and participation has led them to play an influential role in political and social developments and provide a serious basis for creating mass movements with virtual social origins. 
The importance of these media is taken into account that the content they are produced can transfer specific and planned thoughts to the user, and this is similar to the one that easily relates to the subject and the ordinary event turn into a crisis, or by highlighting a specific topic, public opinion will distract users from a distant event, and they will notice something else. Of course, it cannot be ignored that good, accurate and timely information through these networks can prevent the occurrence of various events and crises. In this regard, the activity of social networks, especially by educated young generations, can be somehow effective in the process of socialization and political participation of this stratum. This paper tries to examine this trend by relying on a survey of students from Islamic Azad University, Tehran South Branch. In this regard, the research question is: How have social networks influenced the socialization and political participation of political science students of the Islamic Azad University of South Tehran branch between 2007 and 2017? In response to this question, the following hypothesis is raised.

Hypothesis: The development of social networks based on modern information technologies has caused changes in the values, norms and structures of political socialization among political science students of Islamic Azad University, South Tehran branch during a decade.

\section{Research method:}

According to what is observed, for the explanation of the main question and the proof or non-demonstration of the main hypothesis, other questions were developed based on which a questionnaire was set up. The statistical population of the political sciences students of Islamic Azad University, Tehran South Branch was about 2000 people. Based on the Cochran formula, about 280 people were analyzed as sample population. The questionnaires were distributed to 280 people, so that their research hypotheses were gradually tested based on their responses to the questions. Sub-questions were implicitly and conceptually included among other questions, so that the respondent could not determine which question is related to the research and which is not. Questions were also intermittently tested with other questions in order to measure the validity and reliability of the responses. The statistical population of the 280 people was reduced to 260 people. As 20 students at the very beginning of the time and answer period stated that they are not using social networks at all. This 20-person group could not, in the end, follow along with us, since almost all questions were related to the subject of social networks and how they influenced them, because we wanted to measure how social networks play a role in the socialization and political participation of individuals. The 20 were not just social networking audiences. 
The main purpose of this study was to investigate the role and impact of social networks on socialization and political participation of political students of Islamic Azad University, Tehran South Branch between 2007 and 2017.

Importance and necessity of research:

The dramatic developments in information technology, one of which are now social networks, are in the form of titles such as the era of communications, the explosion of information, the emergence of the information society as well as the digital society, which is an irrefutable reality. This phenomenon can change the fate of a people in a country or even the world in the process of political socialization of societies. In addition, the adaptation of political socialization to the ideals, goals and norms of society can be indicative of the rise of social cohesion and political development. Hence, the study of the process of socialization and political participation in Iran under the influence of new developments such as the expansion of social networks is of strategic importance. The importance of this issue becomes more apparent when it comes to the role of social networks in shaping the transformation of values, norms and political stances among students as future forces of the social fabric. Despite the importance of this, there is little research in this field, and in such a situation, the necessity of analytical and field research in this matter seems to be more.

Information Society and Cyberspace:

The information society today has become a wide range of topics and discourses in such a way as to include issues such as citizens' right to information, participatory democracy, the global intelligence world, and, in general, the supremacy of theoretical knowledge on empiricism. Of course, in the other part, the implications of the information society include the role of oversight, manipulation and direction of thought, the destruction of the public sphere, and the creation of gaps and inequalities at the national and international levels. However, the fact is that the expansion of the intelligence community through modern technology and quick and easy access to information has brought many opportunities and challenges to modern humans.

Cyberspace, which originates from the development of new technologies, contains many and varied information, and as part of the social reality of the new age, it has embraced the core of epistemic interactions. In such a situation, social communication patterns have become more and more evolving and have challenged the social stability and balance that has emerged because of the communication networks of the industrial age. The historic passage from mechanical technology to information and communication technology has 
transformed the nature of communications and made fundamental changes to production processes, power and culture.

Political Socialization:

Political socialization is a continuous process of learning and participation in power and culture, in which individuals, through acquisitions of information and experiences, acquire their duties, rights and roles, especially political duties in society. This process cannot undermine the role of information and the transmission of this information, including information technology and one of its dimensions, social networks.

In the process of political socialization, values, norms, attitudes, customs, and beliefs, including in relation to politics, are passed from one generation to another, and changes or adjustments may occur during this transition. (Alem, 2001: 118). In this regard, social networks as one of the new means of transition can contribute to the process of political socialization and because of social, political and cultural transformations. Of course, this transition starts from the childhood and continues until the middle and end years of his life. Teens and young people are the best option for the transfer of political culture. Each political culture is a specific distribution of attitudes, values, emotions, information and political skills. As people's attitudes affect their actions, the political culture of a nation also affects the behavior of its citizens and its leaders throughout the political system. (J. Mont, 2003: 71)

In the meantime, IT as a global trend, with the ever-increasing expansion of its unique tools and capabilities, has provided a new and more effective ground for the political socialization of people at different levels. In other words, in the new era, the traditional structure of socialization with its basic factors: the family, the media, peer groups, and education, due to inherent constraints and the domination of the political and economic elites, did not allow for the possibility of political socialization in Providing the optimum level, the IT field with its unique characteristics, including censorship, synchronization of communication, interactivity, learning and decentralization (Dehghan, 2005), provides free and equal access to public information for all, facilitates critical rational dialogue In cyberspace, the formation of public opinion and, ultimately, collective political action have also taken place In this way, with the various features available to its users, it has been able to support a wide range of interests.

Social networks and its impact on social transformation:

Social networks have created a new form of communication that, while being massive, is produced and received individually, and influence it. Yet, around the 
world, it has become a tool for social movements. These movements should be able to achieve three goals in order to achieve their goals:

1- Formation of collective identity;

2. Convince their followers,

3. Mobilize followers; these movements can be easily achieved with new information technologies, for all three purposes. (Hamidi, 2011)

In these networks, the effect on public opinion and its mobilization is that, due to these media, a kind of public space forms and many people, without seeing and discussing each other, think each other and, as a result, they act like each other. On this basis, through the production of message, slogan and thought, it is manipulated and mobilized in an artistic way through images, graphics, sound and music, images and beliefs, and ultimately political activity can be achieved. Which is blended with everyday life? In addition, virtual social networks are like a laboratory in which social movements examine their level of ability. In such a case, social networks do not act only as a political means, but they become themselves in the political arena. In this regard, the use of social networks enables this to social movements, which use traditional methods, the protest itself, like marches, encounters, slogans and the use of symbols, can be easily applied and combined with new symbolic methods. Accordingly, these movements have the potential to attract the young class of society and shape public opinion (Hamidi, 2011). Because public opinion is the set of beliefs or thoughts of a group that has focused on a particular topic. Public opinion is a kind of people's judgment in a matter of common discretion at a specific time. Hence, the sum of public opinion is not individual, but the result of individual and collective interaction in a particular cultural, social and economic structure, which in general can be called a kind of social production, which in many cases is determinative and can impose itself on the decisions of a community (Zareiyan, 2006). Some elements related to the concept of public opinion can be categorized as such; public opinion includes behaviors that are spoken by a large number of people and are related to a subject that is considered by all contracts. This is important for everyone. Public opinion is often associated with the intention of participating (with the notion that there are others who act in the same way). Public opinion is expressed with various social instruments and is a social construct (Lazar, 2007). Thus, public opinion is an interactive and dynamic social process in which various thoughts are expressed and ultimately reflected within the framework of a collective manifestation. Accordingly, the existence of social networks that has defeated the monopoly of the media has become a means of informing and raising political awareness of the 
people and because of social transformations. In fact, these new tools simultaneously play several roles; first, it is an easy, up-to-date, low-cost stream of communication between people; a true connection, such as television, radio and the press and, in addition, all users can contribute to the transfer of news and ideas. Moreover, bloggers and other users in these networks criticize official and state media and criticize their orientations, and since many videos and images of events and news is available online to people, there is no longer a place to direct public opinion by providing selective news from official sources. Therefore, most people, rather than pursuing news through the official media of the country, made social networks; networks that themselves were covered by news coverage. On the other hand, these networks have replaced parties and groups and organizations in protest movements, and there is no longer any need for a protest, a member of an organization or special party, nor does it need to be influenced by the leaders of these groups were, in many cases, political leaders who are influenced by the movements of the people who are formed and driven out in these spaces and are analyzing it. Therefore, the use of social networks, despite restrictive measures to government access by users, is an integral part of shaping the anti-government opposition process. Considering the above, we somehow see the impact of social networks in the present time, but to prove this claim, there is a need for different stages of research, multiple research, research in different strata and in different places, so that the extent of this effect has become known.

\section{Background and Literature Research:}

The election campaign is essentially based on communication. In the past decade, with regard to innovation in digital technology, the communications environment has also undergone a change, which has been evident in electoral behaviors, which has required political elites to use new communication tools in the election. Social networks such as Facebook and Twitter, such as sharing audio and video files, are a special communication channel between candidates and voters, which, in addition to providing creative promotional activities, cost less than other traditional media. (Nulty et al, 2016) Today, electoral candidates in Europe provide better interaction with the audience by sending short messages (unlike long and time-consuming texts on their personal sites). (Bode and Dalrymple, 2014) in the 2014 European Parliament elections, for the first time, electoral competition was taking place across the union with new electronic media technology and social networks were an integral part of the campaign, and the results showed that the use of Twitter has been effective on the success of politicians. (Nulty et al., 2016) This result in 
the 2013 Argentine election also confirmed that electoral candidates through Facebook and Twitter had established a constructive relationship with their supporters (Dadamo et al 2016). On the other hand, the younger generation also opts for new social media in political choice and decision-making. In the 2014 local elections in Turkey, 50\% of Twitter users were between 19 and 25 years old, and $70 \%$ of them had access to twitter from a Smartphone, and they used comments for political correspondence (Mengu et al, 2015). Also in the 2010 local elections in Germany, voters affected by the behavioral subjective norm (the influence of family and friends) placed the social network in their electoral campaign. (Schmitt \&Mackenrodt, 2010) Other findings suggest that in the United States, social networks with a religious orientation have positively correlated with increasing audience voting.

\section{Statistical Analysis:}

In this section of the article, statistical analysis and analysis of how the statistical sample is distributed in terms of variables such as gender, age, level of education and marital status of respondents are discussed.

\section{1- Demographic characteristics}

\section{1-1. Gender}

As shown in Table 1-1, out of 280 respondents, about 68\% of them (190) are men and $32 \%$ of them (90) are women. In the following, the abundance (number and percentage) of the respondents' gender status has been determined.

Table 1-1: the sample by gender

\begin{tabular}{|c|c|c|}
\hline$r \quad$ Gende & Abundance & Percent \\
\hline Male & 190 & 68.00 \\
\hline Female & 90 & 32.00 \\
\hline Total & 280 & 100 \\
\hline
\end{tabular}




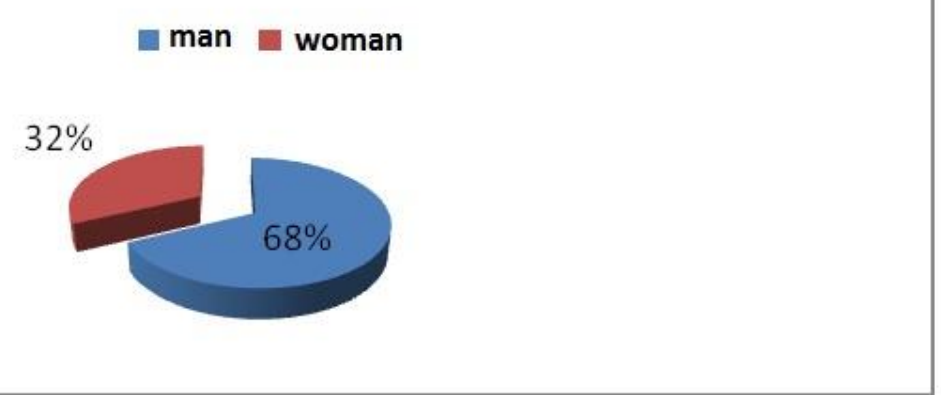

Figure 1-1: sample groups based on gender

1-2- The age of the respondents

2. The age of respondents

According to the findings of Table 1-2 and the responses to the questionnaires, it was determined that about $18 \%$ of respondents (49 people) were less than 30 years old, $36 \%$ of respondents (100 people) aged 30 Up to 40 years old, 33\% of respondents (92 people) aged between 40 and 50 years old and 13\% of respondents (39) are aged 50 and over. In the following, the abundance (number and percentage) of the respondents' age status was determined. From the numbers obtained, it was found that the frequency of age is 30-40 years old.

Table 1 -2: sample groups based on age

\begin{tabular}{|l|l|l|}
\hline Age & Abundance & Percent \\
\hline Less than 30 & 49 & 18.00 \\
\hline Between 30-40 & 100 & 36.00 \\
\hline Between 40-50 & 92 & 33.00 \\
\hline 50 years old & 39 & 13.00 \\
\hline Total & 280 & 100.0 \\
\hline
\end{tabular}

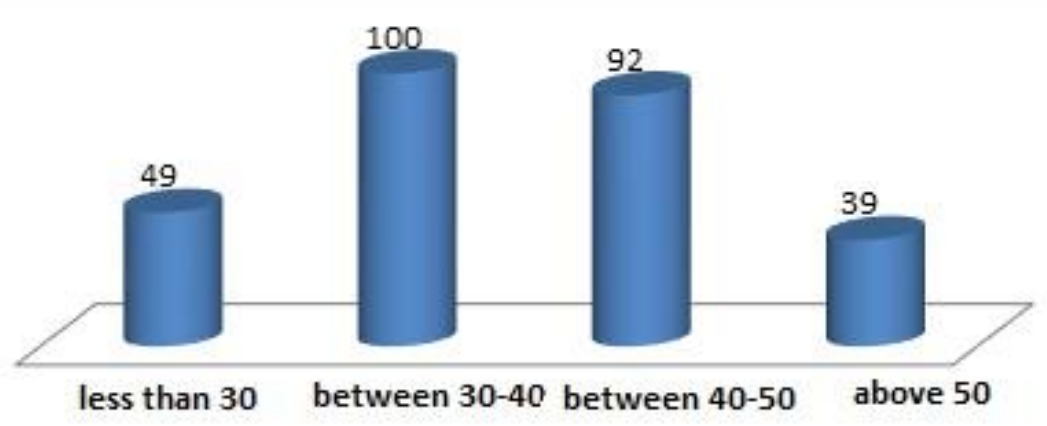

Graph 1 -2 : Sample groups based on age 


\subsection{Education of respondents}

3. The degree of respondents' education

According to the responses to the questionnaires, $23.22 \%$ of the respondents (65) were undergraduate students, $50.00 \%$, (140 students), 26.78\% of respondents (75 students) were Ph.D. students. In the following, the abundance (number and percentage) of the respondents' education curve has been determined.

Table 1 - 3 Number and percentage of respondents by level of education

\begin{tabular}{|l|l|l|}
\hline Education level & Abundance & Percent \\
\hline $\begin{array}{l}\text { Undergraduate } \\
\text { student }\end{array}$ & 65 & 23.22 \\
\hline $\begin{array}{l}\text { Masters } \\
\text { student }\end{array}$ & 140 & 50.00 \\
\hline Ph.D. student & 75 & 26.78 \\
\hline Total & 280 & 100.0 \\
\hline
\end{tabular}

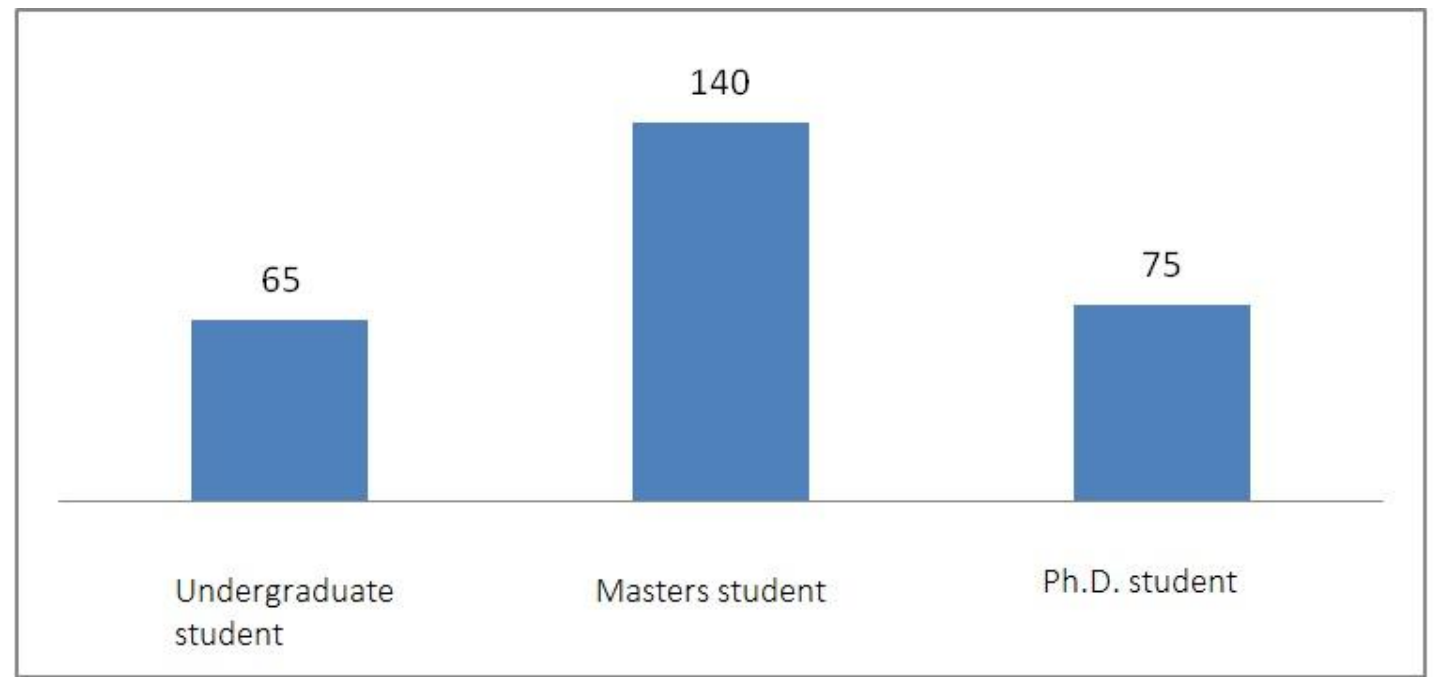

Diagram 1-3: The number and percentage of respondents by level of education 


\section{1-4- marital status}

Table $1-4$ findings indicate that the marital status of the sample group and the percentage is the highest frequency.

Table $1-4$ : Sample individuals based on marital status

\begin{tabular}{|c|c|c|}
\hline work experience & Abundance & Percent \\
\hline Single & 100 & 36.0 \\
\hline Married & 126 & 45. 0 \\
\hline Others & 54 & 19. 0 \\
\hline Total & 280 & 100.0 \\
\hline
\end{tabular}

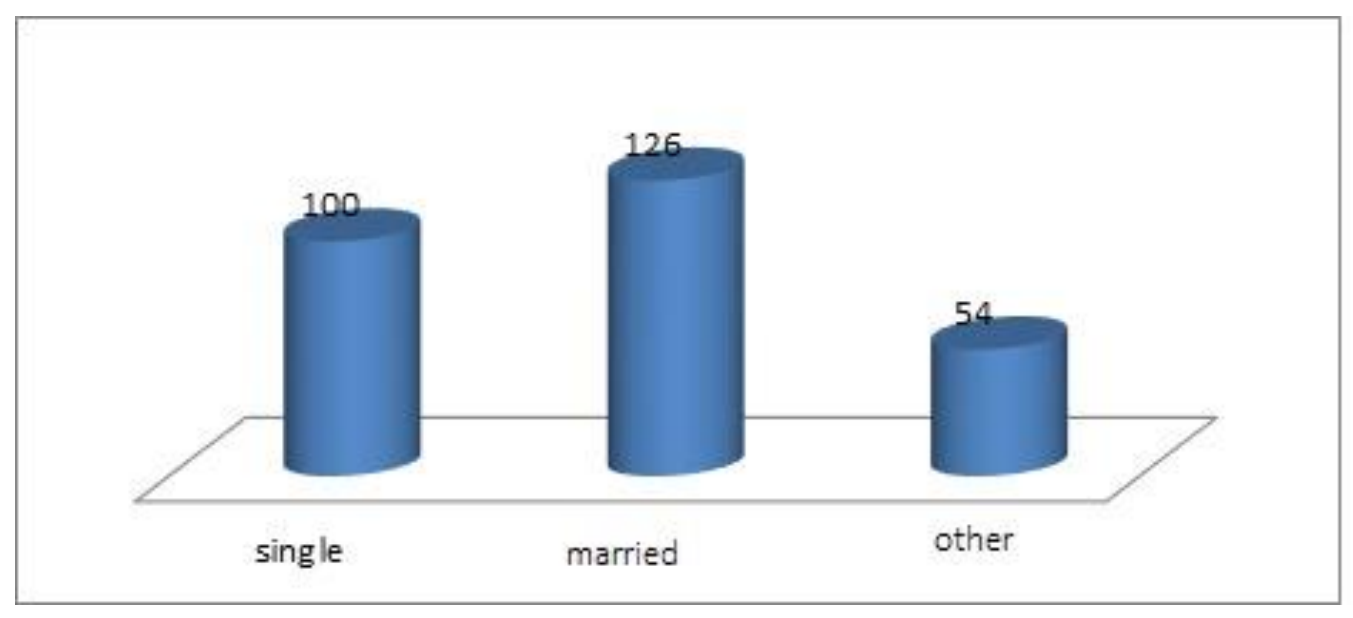

Diagram 1 -4: Sample individuals based on marital status

\section{1-5 - Use of social networks}

As shown in Table 1 -5 it is observed that, out of a total of 280 respondents, $93 \%$ of them (260) use social networks, and $7 \%$ of them (20 people) do not use social networks. In the following, the abundance table (number and percentage) and status charts of the use and non-use of respondents from social networks 
have been identified. From now on, we will use 260 instead of 280 statistics. Because 20 people do not use social networks at all.

Table 1 -5: sample groups based on monitoring the use of social networks

\begin{tabular}{|c|l|l|}
\hline $\begin{array}{l}\text { The use of social } \\
\text { networks }\end{array}$ & Abundance & Percent \\
\hline Yes & 260 & 93.00 \\
\hline No & 20 & 7.00 \\
\hline Total & 280 & 100 \\
\hline
\end{tabular}

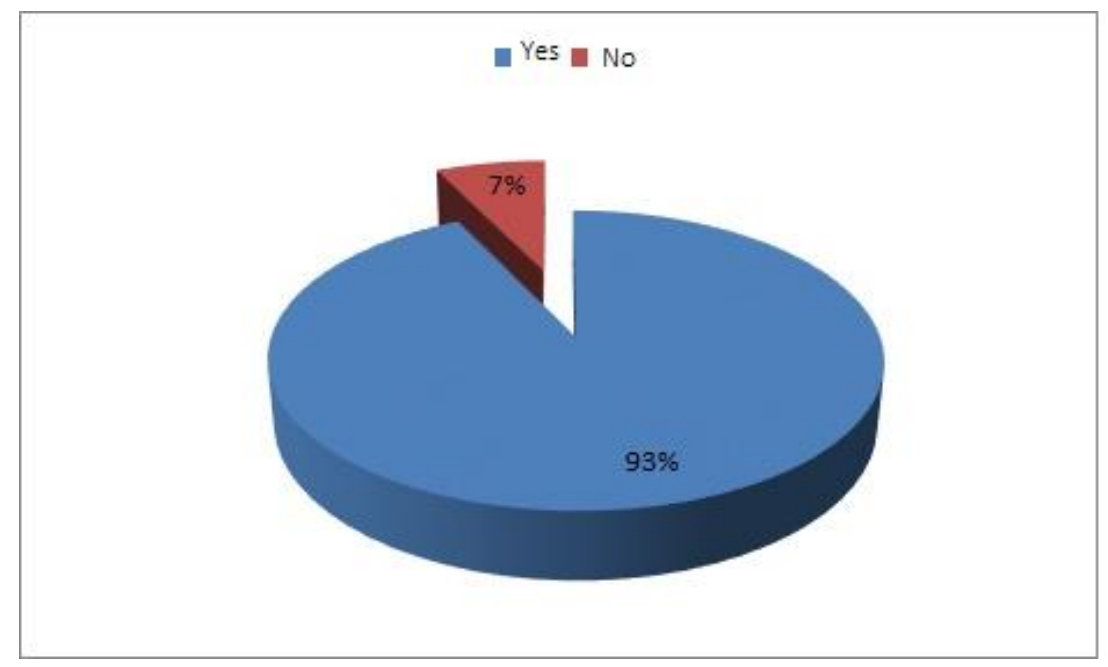

Diagram 1 -5: members of community based on social network use.

Table 1 - 6 the frequency response of variable questions first reading on social networks in terms of political socialization $(260=n)$

\begin{tabular}{|l|l|l|l|l|}
\hline $\begin{array}{l}\text { Your priority in } \\
\text { reading social } \\
\text { networks }\end{array}$ & Abundance & Percent & X2 & $\begin{array}{l}\text { Significance } \\
\text { level }\end{array}$ \\
\cline { 1 - 3 } Political content & 83 & 32.00 & 1.82 & $042 / 0$ \\
\cline { 1 - 3 } $\begin{array}{l}\text { The contents of the } \\
\text { community }\end{array}$ & 58 & $22: 00$ & & \\
\cline { 1 - 3 } Religious Articles & 46 & $18: 00$ & & \\
\cline { 1 - 3 } and read & 73 & 28.00 & & \\
\hline
\end{tabular}




\begin{tabular}{|l|l|l|l|l|}
\hline Total & 260 & 100 & & \\
\hline
\end{tabular}

Table 1-6 shows the descriptive information about the priority variable in reading social networking content in terms of political socialization, in which the abundance of the number of people who have chosen the options for each item is indicated. As can be seen, the results of the X2 Independence test show that there is a significant relationship between the priority in reading social networking content in terms of political socialization $(p<3=d f 1.82=x 2)$.

Table 1 - 7 : frequency response of variable questions the priority of news and political and social developments in terms of political socialization $(260=n)$

\begin{tabular}{|c|c|c|c|c|}
\hline $\begin{array}{l}\text { - Your priority of news and } \\
\text { political developments } \\
\text { notice fromWhat resources }\end{array}$ & Abundance & Percent & $x 2$ & $\begin{array}{l}\text { Significance } \\
\text { level }\end{array}$ \\
\hline IRIB & 80 & 31.00 & \multirow[t]{3}{*}{4.56} & \multirow[t]{3}{*}{.045} \\
\hline Newspaper & 32 & 120.00 & & \\
\hline satellite channels & 50 & 19:00 & & \\
\hline Social Networks & 98 & 380.00 & & \\
\hline Total & 260 & 100 & & \\
\hline
\end{tabular}

Table 1-7 shows the descriptive information about the priority of informing the news and political and social developments of the day, in which the abundance of the number of people who have chosen the options for each item is indicated. As can be seen, the results of the X2 Independence test show that there is a significant relationship between the priority of informing about news and political and social developments of the day in terms of political socialization $(x 4=d f 56=4)$. 
Table 1 - 8 : The frequency response of variable questions, make sure to provide news and information on social networks in terms of political socialization (260 $=\mathrm{n}$ )

\begin{tabular}{|c|c|c|c|c|}
\hline $\begin{array}{l}\text { confidence in the } \\
\text { news } \\
\text { information } \\
\text { provided in social } \\
\text { networks }\end{array}$ & Abundance & Percent & $X 2$ & $\begin{array}{l}\text { Significance } \\
\text { level }\end{array}$ \\
\hline I do not have & 2 & 1.00 & \multirow[t]{6}{*}{1.53} & \multirow[t]{6}{*}{.023} \\
\hline very little & 5 & 2.00 & & \\
\hline Somewhat & 3 & 1.00 & & \\
\hline I have & 70 & 27.00 & & \\
\hline So I & 180 & 69.00 & & \\
\hline Total & 260 & 100 & & \\
\hline
\end{tabular}

Table 1-8 shows the descriptive information about the confidence variable in the news and information provided in social networks in which the abundance of the number of people who have chosen the options for each item indicates as observed. The results of the $\mathrm{X} 2$ Independence test indicate that there is a significant relationship between the reliability of news and information provided in social networks. $(05 / 0 p<4=d f 53 / 1=X 2)$

Table 1-9: Frequency Response of questions ranging presence in the social networks in terms of political socialization $(260=n)$

\begin{tabular}{|l|l|l|l|l|}
\hline $\begin{array}{l}\text { In the recent } \\
\text { elections, was the } \\
\text { social network } \\
\text { effective for your } \\
\text { presence? }\end{array}$ & Abundance & Percent & & $\begin{array}{l}\text { Significance } \\
\text { level }\end{array}$ \\
\cline { 1 - 3 } No effect & 13 & 5.00 & 2.82 & \multirow{2}{*}{.03} \\
\cline { 1 - 3 } Had little effect & 61 & $23: 00$ & & \\
\cline { 1 - 3 } To some extent the & 117 & 45.00 & & \\
\hline The impact & 69 & 27.00 & & \\
\cline { 1 - 3 } Total & 260 & 100 & & \\
\hline
\end{tabular}


Table 1.9. Indicator of the variable information in the recent elections. Social networks were effective in your presence in the election, in which the abundance of people who chose the options for each item. As can be seen, the results of the $X 2$ Independence test show that there is a significant relationship between the priority of informing about news and political and social developments of the day in terms of political socialization $(\mathrm{df2} 2.82 \times 2, p<4)$

Table 1-10: Frequency response of questions ranging political parties and candidates on social networks in terms of political socialization $(260=n)$

\begin{tabular}{|l|l|l|}
\hline $\begin{array}{l}\text { In recent elections, some political } \\
\text { parties and candidates were active } \\
\text { on social networks, whether through } \\
\text { the ads and the candidates are you } \\
\text { become familiar with the views and } \\
\text { positions of these groups }\end{array}$ & & \\
\hline Yes & Abundance & Percent \\
\hline No & 201 & 77.00 \\
\hline Total & 59 & $23: 00$ \\
\hline
\end{tabular}

Table 1-10 indicates that most people in the recent election are active in some political factions and electoral candidates on social networks, and through these advertisements, they are familiar with the views and positions of these groups and candidates.

Table 1 -1 1-frequency response of variable questions about your participation in the elections and the impact of social networks in terms of political socialization

\begin{tabular}{|l|l|l|l|l|}
\hline $\begin{array}{l}\text { In the recent } \\
\text { elections, was the } \\
\text { social network } \\
\text { effective in your } \\
\text { presence in } \\
\text { elections }\end{array}$ & Abundance & Percent & & $\begin{array}{l}\text { Significance } \\
\text { level }\end{array}$ \\
\cline { 1 - 3 } No effect & 20 & 7.00 & \multirow{2}{*}{3.54} & \multirow{2}{*}{.03} \\
\cline { 1 - 3 } Had little effect & 15 & 6.00 & & \\
\cline { 1 - 3 } To some extent the & 85 & 33.00 & & \\
\cline { 1 - 3 } The impact & 140 & 54.00 & & \\
\cline { 1 - 3 } Total & 260 & 100.00 & & \\
\hline
\end{tabular}


Table 1-11 shows the descriptive information about the variable of your election presence on social networks in terms of political socialization, in which the abundance of the number of people who have chosen options for each item is shown. As you can see the results of the X2 Independence Test show that there is a significant relationship between the presences of your election on social networks in terms of the socialization of the media. $(05 / 0 p<4=d f 3.54=X 2)$

Research hypothesis: Social networks have an impact on political socialization

Study hypothesis: social networks affect the political socialization

Table 1-12- reviews hypothesis and the correlation coefficient

\begin{tabular}{|c|c|c|c|}
\hline \multicolumn{2}{|c|}{$\begin{array}{l}\text { Social networks on political } \\
\text { socialization }\end{array}$} & $\begin{array}{l}\text { Social } \\
\text { Networks }\end{array}$ & $\begin{array}{l}\text { Political } \\
\text { socialization }\end{array}$ \\
\hline \multirow[t]{2}{*}{$\begin{array}{l}\text { Social } \\
\text { Networks }\end{array}$} & $\begin{array}{ll}\text { The } & \text { correlation } \\
\text { coefficient } & \end{array}$ & 1 & $0.553^{* *}$ \\
\hline & Significance level & $*$ & 0.001 \\
\hline \multirow[t]{2}{*}{$\begin{array}{l}\text { Political } \\
\text { socialization }\end{array}$} & $\begin{array}{ll}\text { The } & \text { correlation } \\
\text { coefficient } & \end{array}$ & $0.553^{* *}$ & 1 \\
\hline & Significance level & 0.001 & $*$ \\
\hline
\end{tabular}

As the results of Spearman's correlation test between the research variables indicate a significant number observed between social networks and political socialization that is less than 0.01 , and therefore the correlation between these variables is confirmed $(01 / 0>p)$. In addition, due to this connection, the impact of social networks on political participation is also proven.

Diagram 1-6: regression effect of social networks on political socialization and political participation 


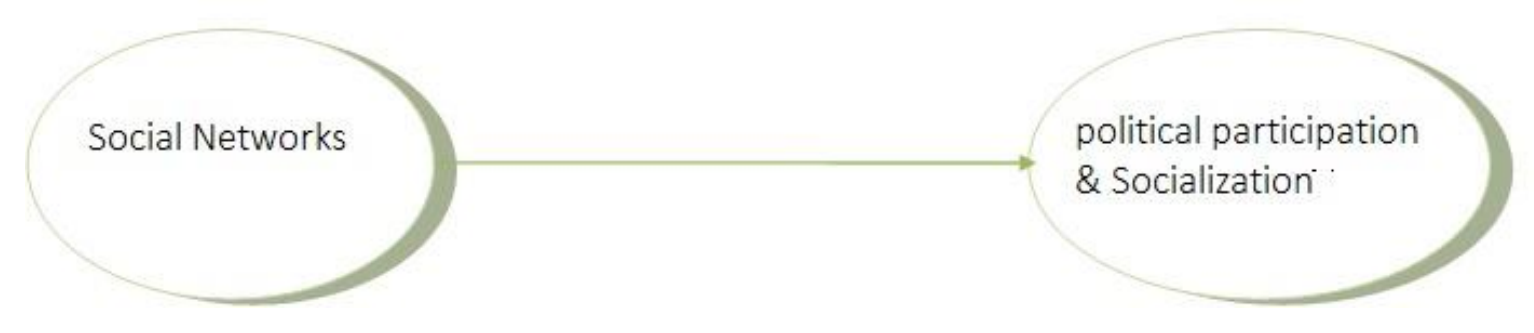

The findings of research:

Based on the findings of this paper, using the results of the correlation and regression tests to investigate the relationship between the development of social networks and political socialization and the result of political participation, the results of this research show that Given that the correlation coefficient for this test was 0.553 , the results show the positive and relatively strong impact of social networks on political socialization. This effect is significant at a confidence level of 99\%. In this sense, according to the respondents of social networking development, based on modern information technologies, they have changed the values, norms and structures of political socialization among political science students of Islamic Azad University in the last decade. Especially that 93\% of those who are questioned about using social networks are using this new communication method. (Table 1-5)

In explaining this finding, according to theoretical approaches, the emergence and expansion of communication in cyberspace, and consequently the application of social networks, has transformed social interactions. These networks have been considered as providing a new way of communicating and sharing content in cyberspace, and today, hundreds of millions of cyber-users are members of various social networks. The results of this study showed that, in addition to the fact that 93\% of respondents use social networks (Table 1-5), 96\% also believe in the news and information provided in these networks. (Table 1-8). Because of this transformation, this network space has largely shaped the interactions of individuals and discursive interactions. In this regard, social networks can be a vehicle for strengthening public debate on a range of issues related to common good and political issues. Specifically, social networking audiences spend a significant amount of social activity on social networks. About 77 percent of 
respondents said they were participating in election campaigns due to social networking ads. (Table 1-10). In this connection, the information revolution in the virtual world has increasingly expanded the role of social networking, and other non-state actors who are challenged as a new online platform and with a new discourse to traditional societies.

Howard Rayon gold, who since 1985, as a member of a virtual community, has been interacting with other members of the network since 1985, is the result of his experiences in developing a theory of the effects of virtual networks on strengthening and consolidating democracy and creating new forms of political participation. Citizens used a virtual public domain. His main idea is that the Internet has created a new era of participatory democracy as a public sphere of politics. He believes that growing online virtual communities can help citizens regain their lost dimensions of democracy and play a more active role in the political process. Therefore, the role of social networks cannot be ignored in shaping public opinion and because of the political developments in the world. Given the fact that social networks in recent years have caused fundamental political and social changes around the world, in Iran, the use of cyberspace in general, and especially social networks, is dramatically influenced by people, parties and groups Before and after the elections held in previous years, and it seems that the use of social networks based on modern information technologies has changed the values, norms and structures of political socialization among individuals.

\section{Conclusion:}

From this paper, we can conclude that modern communication and information technologies can provide an enabling environment for the participation of individuals and political and social groups. Also, cyberspace has become more influential on more informed and more interested individuals than in ordinary and less informed individuals; therefore, access to the Internet and cyberspace is conditional on preconditions such as having computer skills, prior political awareness, Income is enough; it has been more influential on more educated people and having a better financial accountability. Also, cyberspace with unique features such as censorship, synchronization of communication, interactivity, learning and decentralization; providing open access to public information for all and imposing rational, critical conversations in cyberspace and creating public opinion, and ultimately helps collective political action. It also expanded political participation and made people more sociable. Social network users in all political 
arenas with the freedom of expression contained in these networks show more political activity in the real world of the community, and cyberspace, especially social networks with its own unique features, can be the basis for the development of political socialization of individuals. In general, in explaining this finding, given the theoretical approaches and the results of the research, social networks, which are virtual communities of Internet users, have provided a significant part of the time to users' activities and awareness. In fact, the use of social networks is so widespread that the current generation has been named as the generation of networks. Thus, it can be said that virtual social networks increase the level of political knowledge and competencies of individuals to understand and deal with political affairs.

With the increase of political knowledge, the sense of self-efficacy of individuals has also been developed. The feeling that political action can affect the political process has also increased, which has facilitated political participation. In this regard, Wright Philip states; newer news media such as websites, blogs, and virtual networks provide more diverse types of content and more political information, and more non-leaner outlook on traditional news sources such as the newspaper and TV. Meanwhile, these media also provide citizens with the opportunity to increase political knowledge and improve public participation by allowing citizens to create and share information and reveal their identity without revealing their identity. Thus, it can be said that the impact of virtual social networks on the provision of information is obvious, since virtual social networks are the fastest, cheapest and most reliable channel for information distribution, including political information. Virtual social networks, by allowing citizens to access massive amounts of information and formulating online discourse, will inform users of each other's views and provide them with a multidisciplinary understanding of the issues involved and will bring about the transformation of political culture of the nation. This is a way of transferring political ideas and beliefs from one generation to the next, the process that promotes political socialization.

\section{References:}

Alam, Abdul Rahman (2001) Political Science Foundation, Tehran, Publishing Bode, L., Dalrymple, KE, 2014. Politics in 140 characters or less: campaign communication, network interaction, and political participation on twitter.J. Political Mark. (January 2015).

D a Damo, O., Beaudoux, V. \&Kievsky, T. (2016) Political Communication and Social Networks: Analysis of Campaigns for Legislative Elections of 2013 in the City of 
Buenos Aires. Revista Mexicana de Opinión Pública, Julio - diciembre de 2015, ISSN 1870-7300, pp. 107-125.

Dehghan, Alireza (2005) "Internet Gambling" Quarterly Iranian Cultural Studies Association (Internet Specifics and Social Damage), Year 1, No. 2. Hamidi, Sedigheh (2011). The role of social networks in the Egyptian revolution. AlMustafa Al-Allameh Society.

J. Mont, Robert and Gabriel Almond (2002) Theoretical framework for the study of comparative politics, Alireza Tayeb, Tehran, Higher Education and Research Management and Planning Institute

Lazar, Jodit (2007). Public Opinion (Translation by Morteza Written). Tehran: Nizar Nye

Mengu, S., Güçdemir, Y., Ertürk, D. \&Canan, S. (2015) .Political preferences of generation $Y$ university student about governance and social media: A study on March 2014 local elections. Procedia - Social and Behavioral Sciences 174 (2015) $791-797$.

Nulty, Paul, Theocharisb, Y., Popab, A., Parnetc, O., Benoita, K. (2016). Social media and political communication in the 2014 elections to the European Parliament. Electoral Studies, In Press, Corrected Proof.

Schmitt-Beck, R \&Mackenrodt, C. (2010). Social networks and mass media as mobilizes and demobilizes: A study of turnout at a German local election. Electoral Studies Volume 29, Issue 3, Pages 392-404

Zarean, Dawood (2007). Understanding Public Thoughts; Tehran: Academic Jihad 